\title{
Isolated Dislocation of the Scaphoid with Associating Radial Styloid Fracture: A Case Report
}

\author{
Ümit Tuhanıoğlu1, Hakan Çıçek1, Fırat Seyfettinoğlu1 ${ }^{1}$, Hasan Ulaş Oğur¹, Akif Albayrak² \\ ${ }^{1}$ Department of Orthopedics, Adana Numune Education and Research Hospital, Adana, Turkey \\ ${ }^{2}$ Department of Orthopedics, Metin Sabanci Baltalimani Disease of the Bone Education and Research Hospital, \\ İstanbul, Turkey \\ Email: umittuhanioglu@mynet.com
}

Received 3 November 2015; accepted 28 December 2015; published 31 December 2015

Copyright (C) 2015 by authors and Scientific Research Publishing Inc.

This work is licensed under the Creative Commons Attribution International License (CC BY). http://creativecommons.org/licenses/by/4.0/

\section{(c) (i) Open Access}

\begin{abstract}
Isolated dislocation of the carpal scaphoid is a rare injury. Such dislocation is extremely rare. In this article the authors report a twenty-eight-year-old man with isolated dislocation of the scaphoid with associating radial styloid fracture. We manage the patient with open reduction and Kirschner wire fixation. One year later there is a good functional and radiographic result.
\end{abstract}

\section{Keywords}

\section{Scaphoid, Isolated Dislocation, Radial Styloid}

\section{Introduction}

Isolated dislocation of the carpal scaphoid is an extremely rare injury, which is usually accompanied by significant ligamento-capsular lesions [1]. We believe the pathomechanics of this injury to have been a flexion and radial deviation with an axial force on the wrist. Such dislocation is extremely rare. Because of this, treatment strategies can be conflicting and vague current treatment strategies now advocate ligament reconstruction as a first-line treatment to restore normal anatomy and preserve function [2]. The aim of this report is to present a case of isolated dislocation of the scaphoid with radial styloid fracture and present this unusual injury along with its treatment and to attempt to merge the available experience in the literature in a suggested algorithm that will guide the surgeon confronted with this rare problem to treat it promptly and effectively.

\section{Case Presentation}

A twenty-eight-year-old man was first seen at the emergency room with a story of traffic accident. He complained

How to cite this paper: Tuhanıoğlu, Ü., Çıçek, H., Seyfettinoğlu, F., Oğur, H.U. and Albayrak, A. (2015) Isolated Dislocation of the Scaphoid with Associating Radial Styloid Fracture: A Case Report. Case Reports in Clinical Medicine, 4, 381-383.

http://dx.doi.org/10.4236/crcm.2015.412077 
of pain and loss of motion of the right wrist. The initial radiographs demonstrated the proximal pole of the scaphoid to be displaced radial and volar to the radial styloid process and a fracture of radial styloid process (Figure 1(a) and Figure 1(b)). The scaphoid was easily reduced by manipulation of the wrist into ulnar deviation while direct distal pressure was applied over the proximal pole of the scaphoid. The wrist was planned to be immobilized in long-arm cast for six weeks. The patient did not attend at the assessment clinics for six week. At the six-week follow-up, radiographs showed loss of reduction at both scaphoid dislocation and radial styloid fracture. We decided to manage the patient with open reduction and Kirschner wire fixation. An operation performed through a dorsal approach. Complete tears of the scapholunate interosseous, radioscaphocapitate and long radiolunate ligaments were identified. After the reduction of both scaphoid and radial styloid, radial styloid was pinned to capitate through scaphoid (Figure 2(a) and Figure 2(b)). The scapholunate ligament was repaired and reattached with a 2-0 non- absorbable suture. The wrist was immobilized in a neutral position in a long-arm cast for three weeks and an additional three weeks in a short arm cast. Plaster cast and K-wires were removed at six weeks. One year postoperatively the functional result was good. A radiograph showed no sign of avascular necrosis.

\section{Discussion}

A review of the literature found only 29 reported cases. Missed cases for two to four weeks reported in the literature but no reported cases neglected for six weeks [2] [3]. A characteristic radiograph feature that distinguishes dislocation of the scaphoid from perilunate dislocation is the palmar and radial displacement of the proximal pole of the scaphoid out of the scaphoid fossa of the radius. Options for the treatment of dislocation of the scaphoid in the literature include closed reduction and immobilization in a cast, closed reduction and percutaneous pinning, arthroscopically assisted percutaneous pinning and open reduction and internal fixation [4] [5]. An understanding of the anatomy and biomechanical properties of the major periscaphoidal ligaments is critical to the understanding of dislocation of the scaphoid [6] [7]. To achieve exact anatomic reduction of the scapho-lunate diastasis and angulation with closed methods alone is therefore technically demanding and may not be possible. Mayfield et al have described this difficulty with relation to scapholunate dissociation as the scaphoid paradox; to close the scapho-lunate gap radial angulation is required and to obtain correct scapho-lunate angulation ulnar deviation is required [8]. Clearly closed reduction is therefore an inexact procedure and percutaneous pinning across an inexact reduction may produce failure of the wire and the repair. A closed reduction was obtained in our patient at the emergency room but maintainability was not possible.

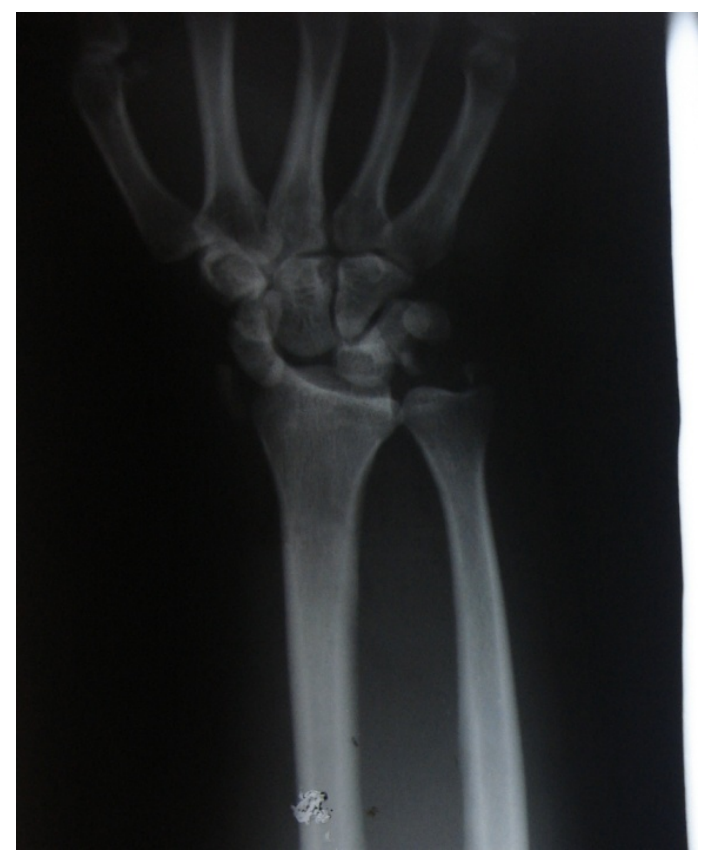

(a)

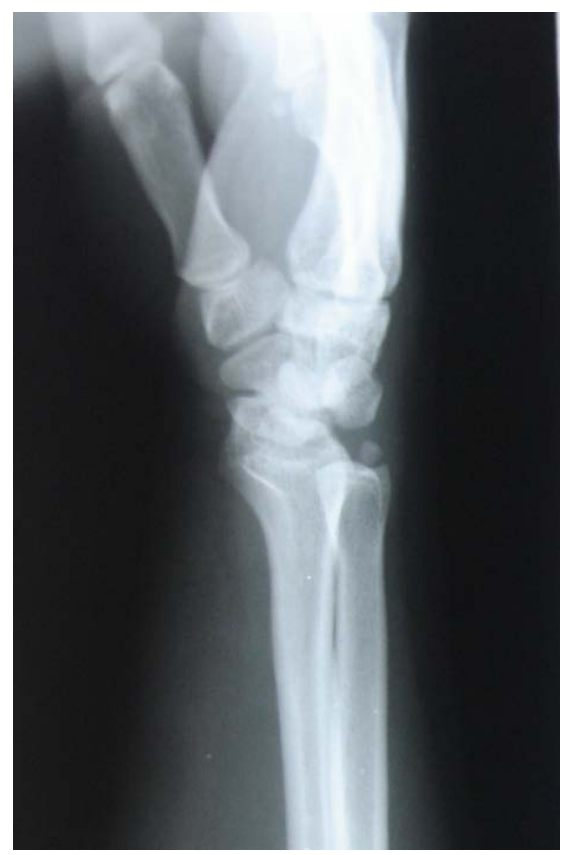

(b)

Figure 1. (a) Preoperative AP radiography; (b) Preoperative lateral radiography. 


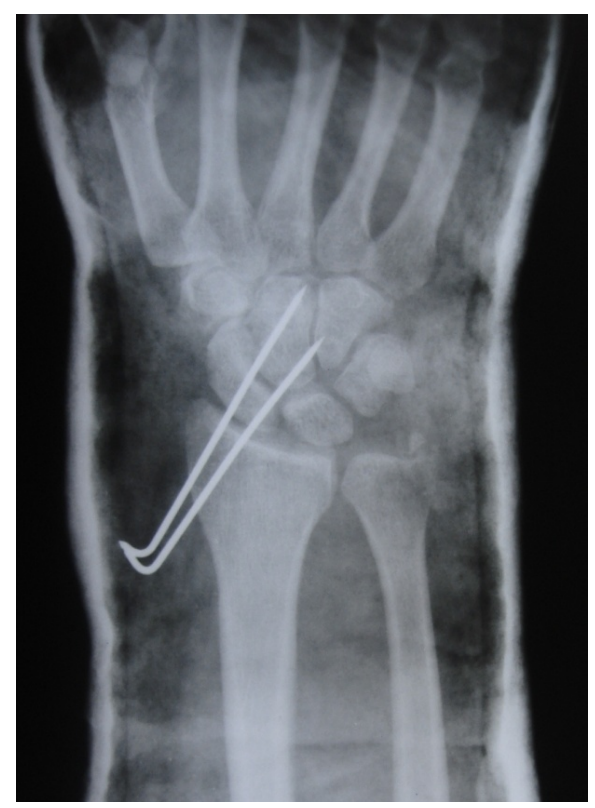

(a)

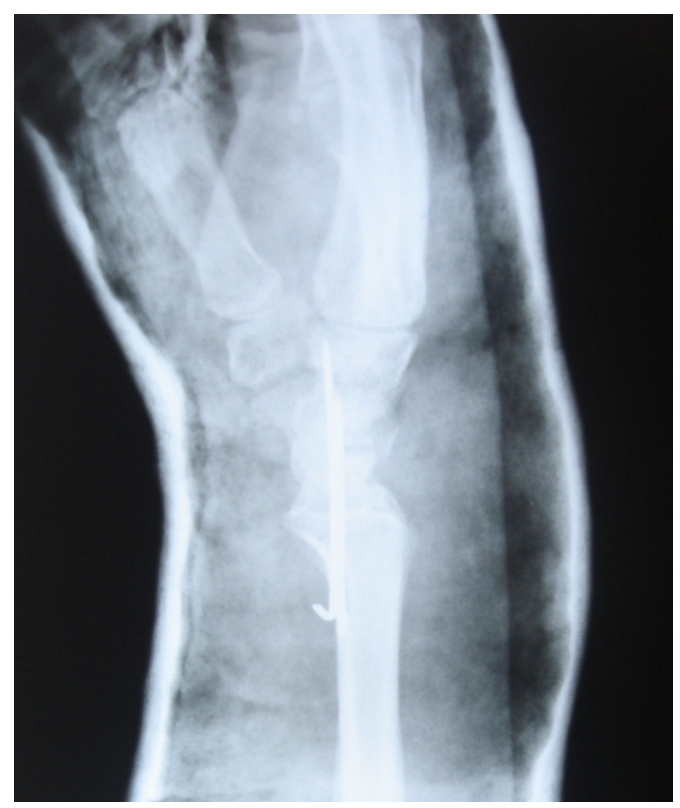

(b)

Figure 2. (a) Postoperative AP radiography; (b) Postoperative lateral radiography.

\section{Conclusion}

Despite reports of successful management with closed reduction and immobilization in a cast alone on the basis of our experience at this patient, we recommend open reduction and percutaneous pinning to help maintain reduction in the cast.

\section{References}

[1] Kiliç, M., Kalali, F., Unlü M. and Yildirim, O.S. (2012) Isolated Carpal Scaphoid Dislocation. Acta Orthopaedica et Traumatologica Turcica, 46, 68-71. http://dx.doi.org/10.3944/AOTT.2012.2493

[2] Cherif, M.R., Ben Ghozlen, R., Chehimi, A., Annabi, H., Trabelsi, M., Mbarek, M. and Ben Hassine, H. (2002) Isolated Dislocation of the Carpal Scaphoid. A Case Report with Review of the Literature. Chirurgie de la Main, 21, 305308. http://dx.doi.org/10.1016/S1297-3203(02)00127-0

[3] Chloros, G.D., Themistocleous, G.S., Zagoreos, N.P., Korres, D.S., Efstathopoulos, D.G. and Soucacos, P.N. (2006) Isolated Dislocation of the Scaphoid. Archives of Orthopaedic and Trauma Surgery, 126, 197-203. http://dx.doi.org/10.1007/s00402-006-0105-X

[4] Kennedy, J.G., O’Connor, P., Brunner, J., Hodgkins, C. and Curtin, J. (2006) Isolated Carpal Scaphoid Dislocation. Acta Orthopaedica Belgica, 72, 478-483.

[5] Kolby, L., Larsen, S., Jørring, S., Sørensen, A.I. and Leicht, P. (2007) Missed Isolated Volar Dislocation of the Scaphoid. Scandinavian Journal of Plastic and Reconstructive Surgery and Hand Surgery, 41, 264-266. http://dx.doi.org/10.1080/02844310600787039

[6] Milankov, M., Somer, T., Jovanovic, A. and Brankov, M. (1994) Isolated Dislocation of the Carpal Scapho1d: Two Case Reports. Journal of Trauma-Injury Infection \& Critical Care, 36, 752-754. http://dx.doi.org/10.1097/00005373-199405000-00030

[7] Wanajo, S., Sato, K., Nakamura, T., Ikegami, H., Tanino, Y. and Toyama, Y. (2008) Isolated Dorsal Fracture-Dislocation of the Scaphoid: A Case Report. Journal of Hand Surgery (European), 33, 311-313. http://dx.doi.org/10.1177/1753193408087072

[8] Mayfield, J.K., Johnson, R.P. and Kilcoyne, R.F. (1976) The Ligaments of the Human Wrist and Their Functional Significance. The Anatomical Record, 186, 417-428. http://dx.doi.org/10.1002/ar.1091860307 